\title{
Psychedelic substance use in the Reddit psychonaut community. A qualitative study on motives and modalities
}

\author{
Jani Pestana, Franca Beccaria and Enrico Petrilli
}

\author{
Jani Pestana is based at \\ EMDAS Program, \\ Università degli Studi del \\ Piemonte Orientale \\ Amedeo Avogadro, \\ Vercelli, Italy. \\ Franca Beccaria is based \\ at Eclectica, Institute for \\ Research and Training, \\ Torino, Italy. Enrico Petrilli is \\ based at the Department of \\ Sociology and Social \\ Research, Università degli \\ Studi di Milano-Bicocca, \\ Milano, Italy.
}

Received 19 March 2020 Revised 15 May 2020 Accepted 29 June 2020

(C) Jani Pestana, Franca Beccaria and Enrico Petrilli. Published by Emerald Publishing Limited. This article is published under the Creative Commons Attribution (CC BY 4.0) licence. Anyone may reproduce, distribute, translate and create derivative works of this article (for both commercial and non-commercial purposes), subject to full attribution to the original publication and authors. The full terms of this licence maybe seen at http://creativecommons.org/licences/by/4.0/ legalcode

The authors would like to thank Fiona Steele for providing a proofread of this article.

\begin{abstract}
Purpose - The purpose of this paper is to investigate motives and modalities of psychedelic substance use in the psychonaut community that is hosted on the Reddit platform (r/psychonaut). Psychonauts are sometimes described as responsible drug users. Elements of responsible use include sharing stories, advice and experiences, reagent testing substances, proper dosing and education on harm reduction and its practical implication. Investigating psychonauts' substance use can highlight what responsible use means for them and could inform best practices for psychedelic use.
\end{abstract}

Design/methodology/approach - Qualitative content analysis of posts and comments on the r/psychonaut subreddit was completed. In total, 350 posts were investigated. A combination of deductive and inductive methods was used to both structure the research and to allow room for novel information. To investigate participant's motives, this combination was used to both collect and analyse the data. To examine modalities, concepts and keywords were formed out of the collected data and then analysed.

Findings - Motives for use ranged from self-knowledge, self-investigation and self-medication to increasing artistic expression, curiosity and recreation. Concerning modalities, the respondents put a high emphasis on preparation, set and setting, integration, dosage and gathering and sharing information through research, articles and trip reports. These features are identified in the literature as elements of responsible drug use. This investigation can help by unearthing best practices already in use by the community to inform the bourgeoning movement of psychedelic substance use - both in a medical and self-reflexive setting.

Originality/value - This paper is framed in the context of paucity of the academic literature on people taking psychedelic substances in Western society in non-rave and non-medical settings, with findings that indicate important change happening in the psychonaut subculture.

Keywords Content analysis, Harm reduction, Motives, Modalities, Psychedelics, Psychonaut Paper type Research paper

\section{Introduction}

The world is seeing a "renaissance" in both interest in and research into psychedelic substances. Although by the end of the 1960s official research was severely limited (Richards, 2015), it has picked up again since the watershed study of Griffiths et al. (2006). During the prohibition years, "counter-expert" (Söderberg, 2016) research and use, however, went underground, and a community of people who continued using and studying psychedelic substances exists to this day. They wrote blogs and hosted websites, held meetings and organized conferences, collecting and sharing anecdotal information on various psychedelic substances. Beyond that, psychedelic substances have continued to be used in different contexts, from MDMA (3, 4-methylenedioxymethamphetamine) in the rave and clubbing scene (Schwartz and Miller, 1997) to various psychedelic substances in the trance festival and party scene (Van Havere et al., 2015). Furthermore, there has been a 
growing trend of micro-dosing psychedelics for different purposes, from increased creativity to a more attuned emotional life (Waldman, 2017; Bosely, 2018).

Currently, much of the research focuses on using psychedelics as an adjunct to psychotherapy for different conditions. They are being (re)evaluated in the treatment of addiction and alcoholism (Garcia-Romeu et al., 2019), depression (Carhart-Harris et al., 2018), post-traumatic stress disorder (PTSD) (Mithoefer et al., 2018) and end-of-life anxiety (Griffiths et al., 2016), while other studies involve Ayahuasca (Dos Santos et al., 2018) and micro-dosing (Polito and Stevenson, 2019). Coming from a different angle, anthropologists have always studied psychedelic use in North and South America (Hunter, 2015), while in recent years, researchers have also started to look at psychedelic use in Western communities (Tramacchi, 2000).

Among the communities of psychedelics enthusiasts exists a subgroup of people who use these substances for their betterment and self-knowledge or auto-gnosis (Móró et al., 2011), a community of people that are described as psychonauts (literally: "sailors of the mind/soul"). This word is attributed to Junger (1970) and refers to persons who seek to "[...] investigate their mind using intentionally altered states of consciousness" (Blom, 2009, p. 434), for a variety of reasons such as spiritual, auto-therapeutic, scientific or research purposes. Psychonauts describe themselves as users who are well-read and prepared regarding their substance use. According to the informal platform PsychonautWiki (2019): "Responsible drug use broadly refers to a set of attitudes and practices intended to maximize the benefits and minimize the harms associated with recreational psychoactive substance use". This set of practices involves reading trip reports, gathering information around optimal dosage, reagent testing substances and sharing stories, advice and experiences. Meanwhile, attitudes include harm reduction and its practical implications (such as those mentioned previously), education and information around substances and learning from past experiences to be safer and more comfortable when taking certain substances (Van Hout and Bingham, 2013; Van Havere et al., 2015). It is important to note that psychonauts do not only use psychoactive substances for their investigations. Other practices include fasting, lucid dreaming, trance dancing and more. We refer to the term psychedelics broadly, including not only the classical psychedelics and their analogues but also substances such as cannabis, MDMA and ketamine that are part of the "psychedelic renaissance" and also used by psychonauts for their investigations (Multidisciplinary Association for Psychedelic Studies, 2020).

Because these compounds are illegal, their in-depth knowledge is relegated to an underground community of "counter-experts" (Söderberg, 2016). As Schifano et al. (2006, p. 644; apostrophes in original) observe, this "pharmacological 'know-how' is often held within groups of users, who exchange information with each other without any contact with the scientific world". O'Brien et al. (2015) even suggest that policymakers should contact cyber-psychonauts for their knowledge, especially of new psychoactive substances. The internet is a vast pool of knowledge on substances that have been "user-tested" for many years, and there are many forums and websites that contain harm reduction information. Of course, these sources of information are informal and sometimes contradictory and incorrect, as they are based on individual experiences.

In the scant literature on the subject, the study of Móró et al. (2011) is only one of a few to delve deeper into the motives of the (online) psychonaut community and investigates whether their drug use results in positive life-changes more often than those who use drugs for other reasons and non-users. Other more recent research into the psychonaut community has dealt with using psychedelic substances for idiosyncratic spirituality (Cohen, 2016; Popovici and Simon, 2017). Framed in the context of the paucity of the academic literature on people taking psychedelic substances in Western society in nonrave and non-medical settings, the main aim of this paper is to contribute and promote this field of research. The study looks into motives and modalities for using psychedelic 
substances among an on-line community of psychonauts on the Reddit platform thus giving a voice to drug users, especially non-problematic users. Along with users' motives, it is essential to focus on the modalities of consumption - e.g. Zinberg's (1984) concept of set and setting. Identifying why and how psychonauts have been using psychedelic substances helps to enlighten this group of users and develop harm reduction practices for other possible users in the future.

\section{Method}

This paper uses qualitative content analysis to collect and investigate data and looks for "underlying themes in the material being analysed" (Bryman, 2016, p. 563). However, qualitative content analysis does not exclude a quantitative dimension. It can use both inductive reasoning, whereby themes and categories emerge from the data and comprise deductive reasoning, where concepts are generated from theory or previous studies (Zhang and Wildemuth, 2017). These concepts are then built upon and revised based on the current research. This is seen as a unique character of qualitative content analysis (Cho and Lee, 2014).

The research material was retrieved from $\mathrm{r} /$ psychonaut - one of the online communities that are hosted on the user-generated-content website Reddit. Although there are many subreddits discussing psychedelics, the r/psychonaut subreddit was chosen because it is the biggest (249.609 members, 14/12/2019) and the oldest dedicated to the topic. The definition of a psychonaut that the subreddit gives itself is "[...] a person who explores activities in which altered stated of consciousness are induced and utilised for spiritual purposes or the exploration of the human condition [...] in order to gain deeper insights into the mind and spirituality". (https://www.reddit.com/r/Psychonaut/, accessed 18/12/2019). By using the r/psychonaut subreddit, we are more certain that these users identify with the term psychonaut or are at least familiar with and relate to it.

When someone opens the Reddit website, different posts from different subreddits (subforums) are visible. A forum user enters a post by clicking it, after which commenting is possible. People can join different subreddits for different topics. Even though usernames on Reddit are completely anonymous, we chose to further obscure them. Both posts and comments on the Reddit forums can be upvoted and downvoted (comparable to giving them a like or a dislike). After six months, Reddit archives threads, so people can no longer vote or comment on them, but they are still readable. This system of upvotes and downvotes may have biased the results because certain kinds of comments and posts are upvoted more and these posts are more readily accessible. However, the bias we observed is a preference for visual posts, while there were no significant differences between substances or types of posts.

A content analysis was made of 350 Reddit threads, i.e. both the original posts and comments. Our research analyses the top posts of all time and the top daily posts in the r/psychonaut subreddit to both see which are the most upvoted posts but also to see what people find important daily. Information was collected from 30 different days within a period of three months, between 5 June and 8 September 2019. Data are divided into two different parts: 200 best of the day and 150 top of all time threads. This decision was made to have both a view across several days and to have an image of what was most upvoted by the community. It also tries to negate the upvoting bias by looking at data through different filters. A coding system was based on three divisions: the type of substance used; the motive(s) of the poster, starting from the concepts of Móró et al. (2011); and the modalities of use, produced by an open coding process.

The type of substance used was coded by name (e.g. LSD, DMT), by the plant producing the desired effect (e.g. mushrooms, Peyote, San Pedro, Ayahuasca) or the popular word for a certain substance (e.g. acid, shrooms). Posts that did not mention any substances or 
other popular words were coded as "no substance". The frequency of each substance identified was measured using a word frequency counter.

The motives of the users were gauged using a semi-open coding process, with the research of Móró et al. (2011) as the basis. According to their research, using psychedelics to "escape from life's troubles" or to "feel good" does not accurately explain their use of psychedelics. They developed a 14-item list of possible purposes for drug use, of which three were termed "AUTO-GNOSIS". For this research, we divided the remaining purposes into different categories: "SELF-ENHANCEMENT" (enhancing mood, avoiding boredom and hopelessness, increasing social contact, increasing sensation and pleasure, stimulating artistic creativity/performance, enhancing physical power); "IDENTITY" (rebellion or alternative lifestyle, building personal identity and drawing attention, expressing membership in a group); and "OTHERS" (out of curiosity). Following the research, we created four extra categories for this last motive (Table 1): "recreation", i.e. when people mention taking substances purely for recreational use; "trip-sitting someone", to indicate that the person took a (lower dose of a) substance to watch their friend(s); "research", when someone took a substance in a research setting; and "no motive mentioned" when it was obvious that the person took a substance but did not give a motive. When nothing was mentioned or could be discerned from the post, it was not included in analysis. An issue with the predefined coding schedule was some categories such as boredom or curiosity could never be ruled out, so they were only coded when explicitly mentioned.

Modalities were coded through open data collection and coding. As many keywords as possible per thread were collected and coded to substance, dosage, preparation, outcomes, harm reduction, trip reports, etc. Sometimes, a keyword was generated out of a phrase or an action. For example, the phrase "I need help processing a $50 \mathrm{mg}$ 4acoDMT trip" was coded as "advice" and "integration". If the person was talking about the environment, in which they ingested the substance, this was coded as "setting". Coding was always done as one word for reasons of analysis. All individual coding was collected and counted using a word frequency counter. The individual coded words were further subdivided into categories of "before", "during", "after", "mode of ingestion" and "other". While motives have been quantified for easier comparison with other studies, quantification for modalities is useful to show users' concerns and interests related to their use.

\section{Table 1 List of drug use purposes}

Auto-gnosis

Self-enhancement

Identity

Other
Religious or spiritual practices

Self-knowledge and self-investigation

Self-medication

Enhancing mood

Avoiding boredom and hopelessness

Offsetting a deficiency

Increasing social contact

Increasing sensation and pleasure

Stimulating artistic creativity

Enhancing physical power

Rebellion or alternative lifestyle

Building personal identity and drawing attention

Expressing membership in a group

Out of curiosity

Recreation

Trip-sitting someone

Research

No motive mentioned 


\section{Results \\ Motives}

A total of 22 different substances were mentioned by the community, with all "classic psychedelics" (LSD, mushrooms, DMT) being present. Other substances such as Ayahuasca (DMT-containing tea), 2C-B and both mescaline-containing cacti (San Pedro and Peyote) were also consumed. Cannabis, MDMA and ketamine are in the list and others less ordinary substances included PCP, methamphetamine and nutmeg. One user took an unknown substance, and one research chemical (1-CP-LSD) was mentioned. Ibogaine, Datura, Nitrous Oxide, Salvia Divinorum, LSA and MDA complete the list.

"Auto-gnosis" is a major motive (45) for ingesting these psychedelic substances (Table 2). It includes "Religious or Spiritual Practices" mentioned only twice, contrary to "SelfKnowledge and Self-Inspection", which were huge motives (27 mentions), being the most frequently cited. A user talks about "Using psychedelics as tools for shadow work (healing trauma)":

I was being presented with a first person view of what enlightenment could feel like and getting a direct reflection or rather a harsh -elf assessment [sic] of my life so far. All my mistakes, or rather, my shadow. (User-1).

"Self-Medication" for various reasons was also a huge factor (16 mentions). One user talks about quitting anti-depressants with the help of psilocybin mushrooms:

Just wanted to share that after 6 years on SSRIs, I quit with the help of psychs [sic]. I feel human again. You are not your thoughts. (User-2)

Other auto-gnostic motives were issues of psychedelics and bi-polarity, helping with porn addiction, with PTSD, with weight-loss and "[ . . becoming] a better person":

4-DMT-dmt, today, has helped me realize how much potential I have, how capable I am of changing myself for the better. (User-3)

\section{Table 2 Motives}

Auto-gnosis

Religious or spiritual practices

Self-knowledge and self-inspection

Self-medication

Self-enhancement

Enhancing mood

Avoiding boredom and hopelessness

Offsetting a deficiency

Increasing social contact

Increasing sensation and pleasure

Stimulating artistic creativity/performance

Enhancing physical power

Identity

Rebellion or alternative lifestyle

Building personal identity/drawing attention

Expressing membership

Other

Curiosity

Recreational

Trip-sitting someone

Scientific research

Total

$\begin{array}{rr}0 & 0 \\ 0 & 0 \\ 0 & 0 \\ 7 & \\ 4 & 6,5 \\ 1 & 13,0 \\ 1 & 0,9 \\ 3 & 0,9 \\ & 100\end{array}$


The second category was given the title "Self-enhancement", with "stimulating artistic creativity/performance" as a majority motive (18 mentions). Although this rarely cited specifically, many times a shared artwork was inspired by an experience with psychedelic substances. Users talked about "How LSD influenced [them] to be a musician" (User-4), or how after taking LSD, they became "really good at mathematics" (User-5). One user attested that psilocybin mushrooms made them realize that "[...] the importance of art in life. Particularly that art is everywhere [...] I began to see my life and everyone's life as the process of creating art". (User-6)

Zero posts dealt with the larger category of "IDENTITY" - no one expressed using psychedelic substances as a form of rebellion, building a personal identity, drawing attention or expressing membership in a community. Either they felt that psychedelic substances were not associated with the need for identity in a community or the r/psychonaut subreddit already gave them a sense of belonging to a community, eliminating the need to express their identity through substance use on this particular forum.

For the final category, "OTHER", recreation and curiosity were mentioned frequently, that is 14 times and 7 times, respectively. Some people also indicated that they had never tried any psychedelic substance or that they were looking for information on best practices. Other users commented giving information on dosage, set and setting and activities to prevent a negative experience. One user asked for advice for his first-time taking LSD:

Like the title says I'm thinking about taking a $1 / 4$ tab or $1 / 2$ tab of acid. The problem is that I get social anxiety when I smoke bud. I don't wanna pop acid and get social anxiety for 8 hours Any advice? (User-7)

The advice they got in reply ranged from "don't smoke bud and don't be alone" to having a solid set and setting, drinking enough water and having Benadryl (anti-histamine) ready to cut-off a potentially bad experience. In this case, there was no mention of the possible sideeffects of combining sedating anti-histamines with psychedelics, showing the limitations of users' chemical knowledge.

These different motives show that for psychonauts taking these substances is not an impulsive decision but a deliberate one. In most instances, users had a direction and were undertaking what they thought were the necessary steps to safely navigate the terrain. These steps are highlighted in the modalities.

\section{Modalities}

Regarding modalities, the keyword "dosage" was most present (39 times), referring to any known dosage of ingestion, whether it be a high or a low one. Set (10) and setting (26) were also high in frequency. It was noticeable that people transitioned between settings, e.g. starting at home and transitioning into nature:

[...] I soon became very uncomfortable in the environment I was tripping in - my parents' house [.. .] I tried to let go and fall into the hands of the trip, but my anxiety about my situation prevented me from doing so. Instead I left the house and went to the river. (User-8)

Often, when people were having an unpleasant experience, and this was owing to an unpleasant setting, such as their parents' house. One user described that they went to a political rally on acid and had "super bad vibes". They admit that it was a "stupid idea to begin with" (User-9).

Another keyword often mentioned is trip-sitter (10), meaning that people called on others to guide them in their experiences. Even though trip-sitting was not often a motive for substance use, users frequently wanted people to trip-sit for them. However, in other instances being alone (8) was exactly what was wanted, especially in combination with selfrealization as a motive for using the substance. Sharing information such as scientific 
research was important (21), while general information (e.g. newspapers, other internet sources, other posts and other users) was also freely shared (18). Users made trip reports (20) of their experiences and harm reduction measures were discussed widely (13). One user specifically asked the moderators of the forum to have a "sticky post" - a post that will purposefully remain at the top so anyone entering the forum immediately sees it. They asked to fill it with harm reduction information so anyone can easily access this:

If we are wanting decriminalisation shouldn't we be setting good examples for that cause and promote safety right out front for all to see as the first thing here? [...] I think this is especially important now with the rising use of these substances and new people coming to these subs [fora]. (User-10)

Relatively few posts (14) discussed the mode of ingestion of the drug. This may be because many of the discussed drugs in question have one clear, common method of ingestion. However, one person mentioned "boofing" or anally inserting LSD, and another made mention of an intravenous injection of DMT in a research setting. One poster made a "Iemon tek" of their psilocybin mushrooms, which suggests that a lemon can be used to jumpstart the conversion of psilocybin (the pro-drug) into psilocin (the actual hallucinogen) that is normally done by the stomach.

Data about modalities can also be distinguished based on their temporality (Table 3). The category "Before" includes keywords such as harm reduction, information, research and advice. Users asked questions and commenters gave advice, which was mostly constructive: not dosing too high, having a trip-sitter, not mixing substances, reading up beforehand and being in the right setting. Some advice contradicted harm reduction standards, such as high doses that were not seen as problematic. Follow up comments would then be made regarding the contradictory information.

During keywords describe techniques or activities for harm reduction during the experience and include meditation, trip sitter, calming audio, friend, home, guided - and activities, i.e. painting or vaporizing. Experiences often come to the foreground, i.e. surrender, overwhelming, ego-death (or ego dissolution), synchronicity, therapeutic and recreational. Set and setting are discussed often - alone, darkness, music, nature, home - showing that these considerations are important for many people.

"After" the experience, users mostly reference whether it was a good or bad experience for them, what the impact on their life was (e.g. life-changing, life-questioning, one person mentioned eating a lot of fruits and vegetables, with many commenters talking about turning vegetarian and vegan after a psychedelic experience) and importantly, how to cope with the aftermath. A lot of keywords mention techniques for integrating the experience such as journaling, abstinence, meditation and seeking help from a therapist. The negative effects are also discussed, such as hallucinogen persisting perception disorder (HPPD). Several people mentioned having difficult or unpleasant experiences or that the outcomes were negative. Salvia Divinorum was considered as responsible for a lot of unpleasant

Table 3 Temporal dimension of modalities

\begin{tabular}{|c|c|c|}
\hline Before & During & After \\
\hline $\begin{array}{l}\text { Harm reduction advice: dosage, } \\
\text { preparation, acquirement, intention, } \\
\text { set and setting, good or bad, dieting, } \\
\text { trip sitter and not mixing substances } \\
\text { Information: doing research, reading } \\
\text { up }\end{array}$ & $\begin{array}{l}\text { Set and setting: music vs silence, tripsitter vs } \\
\text { solo and location } \\
\text { Experience: positive vs negative, confusion, } \\
\text { unity, ego-death, overwhelming and surrender } \\
\text { Harm reduction techniques or activities: } \\
\text { meditation, painting, calming audio and } \\
\text { tripsitter }\end{array}$ & $\begin{array}{l}\text { Integration: therapy, support, community, } \\
\text { journaling, abstinence, meditation and writing } \\
\text { Experiences: positive vs negative, HPPD, } \\
\text { difficult, suicide, better unity of mind and body, } \\
\text { trauma-recovery, therapeutic, psychosis and } \\
\text { addiction recovery } \\
\text { Impact: life-changing, life-questioning, turning } \\
\text { vegetarian or vegan }\end{array}$ \\
\hline
\end{tabular}


experiences and dosages being too high is another factor that contributed to this. A particularly upsetting post involved a woman writing on behalf of her deceased husband who had committed suicide, possibly during a psilocybin experience.

An important topic about modalities is risk management, both in the procurement of substances and in their ingestion, during the experience and in the aftermath. One way in which users circumvent the illegal market is by growing own mushrooms or going out and collecting them in nature, while one user synthesized their own DMT vape pens. But from this data, it is impossible to deduct the amount and kind of interaction with illegal drug markets.

A significant risk management strategy continues to be the dissemination of information through research and anecdotal evidence in the form of trip reports so that other users could read up and implement strategies that have been investigated scientifically or anecdotally. Users would generally practice risk management strategies, such as being aware of their set and setting, sharing research and information about psychedelic substances, being aware of dosage, calling on trip-sitters and the community for guidance. During the experience, there is an emphasis on safety, on setting (alone in darkness or being in nature) and on activities to manage negative experiences (meditation, trip sitters and guides, listening to calming audio). Risk management is not always successful and depends on many factors, as shown by keywords such as overwhelming, paranoia and bad setting (see quote below). Throughout the analysis process, an ill-considered setting often resulted in a difficult or challenging experience for the user.

The aftermath of the experience often gets overlooked. They can be overwhelming - as can be seen in keywords such as life-questioning and life-changing - and steps must be taken to integrate these experiences. Integration is seen as important for long-term well-being. Users indicated that they would stop using psychedelic substances for an unspecified amount of time or were encouraged to do so to work on integration alone or with a therapist and that they found great comfort journaling and finding support in the r/psychonaut community.

Users mostly reported positive outcomes, citing life-changing experiences, becoming vegetarian or vegan, having deeper gratitude or experiencing a better connection between their body and mind. Nonetheless, negative experiences should not be overlooked, and several users reported developing HPPD, having episodes of psychosis, having difficult integration processes and (as mentioned earlier) a possible psilocybin-linked suicide. Still, in the majority of instances, the use of psychedelics is seen as something positive and something that can yield great benefits if done with care.

\section{Discussion}

This research uses qualitative content analysis to give an account of non-medical and nonceremonial substance use. An online community of users was investigated for whom substance use is part of their life but not culturally imbedded into the larger whole of society, in the style of current anthropological research (Tramacchi, 2000; Ruane, 2018).

The r/psychonaut sub-forum describes a psychonaut as someone who uses altered states of consciousness to gain deeper insights in their mind and into spirituality. This definition is similar to the one that was propagated by Junger (1970). Although the definition of Junger includes all manners of entering an altered state of consciousness (including fasting, drumming, trance dance and others), the majority of posts included substance use to achieve this. In total, 22 unique substances were identified during the research. Apart from the classic psychedelics such as psilocybin, LSD and DMT, there was mention of Ayahuasca, Ibogaine and 2C-B and also non-psychedelics such as nutmeg, Datura, PCP, methamphetamine and the research chemical 1-CP-LSD. Psilocybin was by far the most 
used substance. The diversity of substances is unsurprising given that psychonauts tend to use multiple avenues for their investigations.

Our research shows a significant difference to the existing literature on psychonauts' motives. Like in Móró et al.'s research, auto-gnosis is a major reason why the r/psychonaut community chooses to ingest psychedelic substances, but unlike their research, we found selfinvestigative and self-medicative motives to be far more prevalent than religious ones. The idiosyncratic spirituality and neo-shamanisms of the psychonaut community, talked about by Cohen (2016), Popovici and Simon (2017) and Orsolini et al. (2017) were rarely encountered. While self-enhancement was a key motive for ingesting psychedelic substances, with enhanced artistic creativity often mentioned, these motives for drug use are seldomly highlighted either in research or wider societal debates. Remarkably, no one indicated using psychedelic substances for identity building, contrary to the findings of Móró et al. (2011). We can speculate that they did not feel that they needed to use psychedelic substances to create an identity, or maybe this is because they already identified as psychonauts, also by being part of the r/psychonaut community. Finally, curiosity did not factor in the psychonaut community. This is not surprising; the people who already consider themselves to be psychonauts have previously experimented with these substances.

Frequently, psychonauts consider themselves to be responsible drug users, and a definition of responsible use is part of the PsychonautWiki (2019). This definition includes an emphasis on harm reduction practices and the maximization of benefits. Van Hout and Bingham (2013) identified lab testing, knowing your dosage and reading trip reports as critical elements while gathering information, in general, is seen as important, and Van Havere et al. (2015) talks about learning from past experiences. Posts and comments show that the members of the $\mathrm{r} /$ psychonaut forum are not only aware of these elements but also engage with them; they measure dosage, use reagents to test their substances, write trip reports, share and read information and thus learn from previous experiences by themselves and others, as mentioned by Van Havere et al. (2015). Awareness is shown of the importance of dosing, mental set and measures of precaution such as being in the right environment or setting.

Decriminalization, scientific research and information are terms which all scored high in the count, indicating that the community finds it important to inform others and themselves about harm reduction and responsible drug use. Results confirm Schifano et al.'s (2006) statement that the (pharmacological) know-how of the psychonaut group is extensive, and Söderberg, (2016) talks about "counter-expertise": a pool consisting of many years of usertested knowledge on substances that are illegal for science to research. However, this underground knowledge remains imperfect, as demonstrated by the lemon tek and Benadryl cases. Consequently, these forums could benefit from external harm reduction interventions that provide more accurate information.

Newcombe and Johnson (1999) found that the setting for psychedelic experiences turned out to be normal and everyday settings. R/psychonaut corroborates these findings. In the majority of cases, the setting was their home or their friends' home, and many psychonauts ventured into nature. Retreats or a ceremonial setting proved not as frequent. Setting proved to be a key factor in having a positive experience. Psychonauts mentioned moving from unpleasant settings to pleasant settings, such as from a house with parents to a park or forest. The study shows that although not embedded in an accepted societal context, the psychonaut community often finds the use of psychedelic substances meaningful. The term "life-changing" was coded several times, and two people indicated becoming vegetarian as a result of their experiences. Furthermore, many posts talked about integrating the experience into everyday life.

Finally, new psychedelic research is on the rise, many decriminalization efforts are underway in the USA and many other countries around the world (Decorte, 2018; 
Shanahan and Cyrenne, 2019), and chances are increasing that one day, psychedelic substances will be legal in society again. Combine this with the fact that the popularity of psychedelic substances never subsided, and the importance of reflection and development of best practices for use and harm reduction becomes apparent. From the research on modalities, a script for best practices can be drafted. There are three phases (before, during and after) to keep into account, and each phase emphasizes slightly different elements. Before the experience, the emphasis is on preparation and intention, why and how. During the experience, the emphasis shifts to techniques for having the best possible experience: set and setting, silence or music, alone or with a trip sitter or friends and activities to guide the experience. Then after the experience comes the integration of positive, difficult or negative experiences through therapy, journaling and practices such as drawing, meditation, finding a community or abstinence from drugs. Pursuing further research into individual experiences is also a significant factor. Together, this creates a user-experience template for having a psychedelic experience in a non-medical and nonrave context that can be used to inform harm-reduction policies.

\section{Conclusion}

This study adds to the literature on people taking psychedelic substances in Western society in a non-rave setting and non-medical setting. The focus is on the experiences of regular users, their motives and modalities of use. By relating the psychedelic renaissance with the small numbers of "religious or spiritual practices" and "identity" motives and the less frequent ceremonial or retreat setting, and contrasting this with the high number of users whose motive is "self-knowledge and self-inspection" and "stimulating artistic creativity and performance", our results seem to indicate that contemporary psychedelic culture might be moving in two directions. One is characterized by a more traditional collective neo-pagan approach as seen in the research of Móró et al., 2011, where ceremony and shamanic guidance have great importance, while the other is more secularized, distinguished by a more individualistic, rational and hands-on approach to drug use. More research into the motives of both groups of users, their differences and their similarities is needed.

However, the growing individualistic and performative ways of psychedelic substance use do not mean that these psychonaut users are partaking in substance use in random or dangerous ways. Our research indicates risk management at different levels, from ideational to practical. From the research on modalities, we can see that many users emphasize intention. Intention is tied to motive - why use a psychedelic substance and what is the desired outcome? Our study indicates that users seek to improve or selfmedicate and that they actively seek out ways to manage the risks that come with their use to have the best outcome. In the face of prohibition, without scientific research to help them, psychonaut substance users self-organized on the internet to try and accurately research the substances they were using and implement best practices for responsible use for themselves and others, in contrast to stereotypical depictions of drug users who search for nothing more than their next fix.

The main limitation of the research is that subreddits tend to increase in visual content when they increase in membership size because an image is easier consumed and upvoted than a 500-word post or an in-depth discussion. Therefore, many of the posts suffered from a lack of analysable content. These posts were left out of the analysis, so they could not skew the data. Another issue is that in the analysis of different substances, in 164 out of 350 posts no substance was cited. The same happened for motives in 219 out of 350 posts. For modalities, the number was the same as for substances. The reason for the discrepancy between substances and modalities on the one hand and motives on the other is that some posts were coded for a substance and a modality, while motive was irrelevant, e.g. posts that contained research into psychedelics or efforts to decriminalize psilocybin mushrooms. 


\section{References}

Blom, J.D. (2009), A Dictionairy of Hallucinations, Springer, New York, NY.

Bosely, S. (2018), "First ever trials on the effects of microdosing LSD set to begin", available at: https:// www.theguardian.com/science/2018/sep/01/first-ever-trials-on-the-effects-of-microdosing-lsd-setto-begin (accessed: 18 June 2019).

Bryman, A. (2016), "Documents as sources of data", in Bryman, A. (Ed.), Social Research Methods, 5th ed., Oxford University Press, Oxford, pp. 545-568.

Carhart-Harris, R.L., Bolstridge, M., Day, C.M.J., Rucker, J., Watts, R., Erritzoe, D.E., Kaelen, M., Giribaldi, B., Bloomfield, M., Pilling, S. and Rickard, J.A. (2018), "Psilocybin with psychological support for treatment-resistant depression: six month follow-u", Psychopharmacology, Vol. 235 No. 2, pp. 399-408.

Cho, J.Y. and Lee, E-h. (2014), "Reducing confusion about grounded theory and qualitative content analysis: similarities and differences", The Qualitative Report, Vol. 19 No. 32, pp. 1-20.

Cohen, E. (2016), "Psychedelics and the spiritual path - critical voices and considerations", Transpersonal Psychology Review, Vol. 18 No. 1.

Decorte, T. (2018), Regulating Cannabis: A Detailed Scenario for a Nonprofit Cannabis Market, Archway Publishing, Bloomington.

Dos Santos, R.G., Sanches, R.F., Osório, F.D.L. and Hallak, J.E.C. (2018), "Long-term effects of ayahuasca in patients with recurrent depression: a 5-year qualitative follow-up", Archives of Clinical Psychiatry, Vol. 45 No. 1, pp. 22-24.

Garcia-Romeu, A., Davis, A.K., Erowid, F., Erowid, E., Griffiths, R.R. and Johnson, M.W. (2019), "Cessation and reduction in alcohol consumption and misuse after psychedelic use", Journal of Psychopharmacology, Vol. 33 No. 9, pp. 1-14.

Griffiths, R.R., Richards, W.A., McCann, U. and Jesse, R. (2006), "Psilocybin can occasion mystical-type experiences having substantial and sustained personal meaning and spiritual significance", Journal of Psychopharmacology, Vol. 187 No. 3, pp. 268-283.

Griffiths, R.R., Johnson, M.W., Carducci, M.A., Umbricht, A., Richards, W.A., Richards, B.D. and Klinedinst, M.A. (2016), "Psilocybin produces substantial and sustained decreases in depression and anxiety in patients with life-threatening cancer: a randomized double-blind trial", Journal of Psychopharmacology, Vol. 30 No. 12, pp. 1181-1197.

Hunter, J. (2015), "Beyond Castaneda: a brief history of psychedelics in Anthropology", in King, D., Luke, D., Sessa, B., Adams, C. and Tollan, A.(Eds), Neurotransmissions: essays on Psychedelics from Breaking Convention, Strange Attractor Press, London, pp. 125-133.

Junger, E. (1970), Annaherungen: Drogen und Rausch. s.I.:s.n.

Mithoefer, M.C., Mithoefer, A.T., Feduccia, A.A., Jerome, L., Wagner, M., Wymer, J., Holland, J., Hamilton, S., Yazar-Klosinski, B., Emerson, A. and Doblin, R. (2018), "3,4-methylenedioxymethamphetamine (MDMA)assisted psychotherapy for post-traumatic stress disorder in military veterans, firefighters, and police officers: a randomised, double-blind, dose-response, phase 2 clinical trial", The Lancet Psychiatry, Vol. 5 No. 6, pp. 486-497.

Móró, L., Simon, K., Bárd, I. and Rácz, J. (2011), "Voice of the psychonauts: coping, life purpose, and spirituality in psychedelic drug users", Journal of Psychoactive Drugs, Vol. 43 No. 3, pp. 188-198.

Multidisciplinary Association for Psychedelic Studies, (2020), Research, available at: https://maps.org/ research (accessed 6 May 2020).

Newcombe, R. and Johnson, M. (1999), Psychonautics: A Model and Method for Exploring the Subjective Effects of Psychoactive Drugs, Newcombe, Liverpool.

O’Brien, K., Chatwin, C., Jenkins, C. and Measham, F. (2015), "New psychoactive substances and British drug policy: a view from the cyber-psychonauts", Drugs: Education, Prevention and Policy, Vol. 22 No. 3, pp. 217-223.

Orsolini, L., St John-Smith, P., McQueen, D., Papanti, D., Corkery, J. and Schifano, F. (2017), "Evolutionary considerations on the emerging subculture of the e-psychonauts and the novel psychoactive substances: a comeback to the shamanism?", Current Neuropharmacology, Vol. 15 No. 5, pp. 731-737.

Polito, V. and Stevenson, R.J. (2019), "A systematic study of microdosing psychedelics", PLoS One, Vol. 14 No. 2. 
Popovici, A.-F. and Simon, R.M. (2017), "Searching for spirituality through the use of psychedelic drugs: the case of psychonauts", Journal of Experiential Psychotherapy, Vol. 20 No. 2, pp. 32-36.

PsychonautWiki (2019), "Responsible drug use", available at: https://psychonautwiki.org/wiki/ Responsible_drug_use (accessed 16 June 2019).

Richards, W.A. (2015), Sacred Knowledge: Psychedelics and Religious Experiences, 1st ed., Colombia University Press, New York, NY.

Ruane, D. (2018), "Field experiments: psychonauts' efforts to reduce the harm of old and new drugs at music festivals", Drugs: Education, Prevention and Policy, Vol. 25 No. 4, pp. 337-344.

Schifano, F., Deluca, P., Baldacchino, A., Peltoniemi, T., Scherbaum, N., Torrens, M., Farre, M., Flores, I., Rossi, M., Eastwood, D., Guionnet, C., Rawaf, S., Agosti, L., Di Furia, L., Brigada, R., Majava, A., Siemann, H., Leoni, M., Tomasin, A., Rovetto, F. and Ghodse, A.H. (2006), "Drugs on the web; the psychonaut 2002 EU project", Progress in Neuro-Psychopharmacology and Biological Psychiatry, Vol. 30 No. 4, pp. 640-646.

Schwartz, R.H. and Miller, N.S. (1997), "MDMA (ecstasy) and the rave: a review", PEDIATRICS, Vol. 100 No. 4, pp. 705-708.

Shanahan, M. and Cyrenne, P. (2019), "Cannabis policies in Canada: how will we know which is best?", International Journal of Drug Policy, available online (accessed 26 September 2019).

Söderberg, J. (2016), "DIY research in the psychonaut subculture. A case of unwanted user innovation", in Hyysalo, S., Jensen, T.E. and Oudshoorn, N. (Eds), The New Production of Users: Changing Innovation Collection and Involvement Strategies, Routledge, New York, NY, pp. 297-323.

Tramacchi, D. (2000), "Field tripping: psychedelic communitas and ritual in the Australian bush", Journal of Contemporary Religion, Vol. 15 No. 2, pp. 201-213.

Van Havere, T., Tutenges, S., De Maeyer, J., Broekaert, E. and Vanderplasschen, W. (2015), "Keep an eye on your friends, even when you don't know them': drug use and harm reduction in the Goa trance scene in Belgium", Drugs: Education, Prevention and Policy, Vol. 22 No. 3, pp. 239-247.

Van Hout, M.C. and Bingham, T. (2013), "urfing the silk road': a study of users' experiences", International Journal of Drug Policy, Vol. 24 No. 6, pp. 524-529.

Waldman, A. (2017), "A really good day: how microdosing made a mega difference in my mood, my marriage and my life", s.l.:Corsair.

Zhang, Y. and Wildemuth, B.M. (2017), "Qualitative analysis of Content", in Wildemuth, B.M. (Ed.), Applications of Social Research Methods to Questions in Information and Library Science, Libraries Unlimited, Santa Barbara, pp. 318-329.

Zinberg, N. (1984), Drug, Set and Setting: The Basis for Controlled Intoxicant Use, Yale University Press, Yale.

\section{Further reading}

Pardes, A. (2018), "The inside story of Reddit's redesign", available at: https://www.wired.com/story/ reddit-redesign/ (accessed 23 June 2019).

Peacock, A., Bruno, R., Gisev, N., Degenhardt, L., Hall, W., Sedefov, R., White, J., Thomas, K.V., Farrell, M. and Griffiths, P. (2019), "New psychoactive substances: challenges for drug surveillance, control, and public health responses", The Lancet, Vol. 394 No. 10209, pp. 1668-1684.

Pollan, M. (2018), How to Change Your Mind: What the New Science of Psychedelics Teaches Us about Consciousness, Dying, Addiction, Depression, and Transcendence, 1st ed., Random House Large Print, New York, NY.

\section{Corresponding author}

Enrico Petrilli can be contacted at: enrico.petrilli@unimib.it

For instructions on how to order reprints of this article, please visit our website: www.emeraldgrouppublishing.com/licensing/reprints.htm

Or contact us for further details: permissions@emeraldinsight.com 